\title{
Small-scale spatial variation in rates of metacercarial accumulation by a bivalve second intermediate host
}

\author{
R. Poulin* and K.N. Mouritsen ${ }^{\dagger}$ \\ Department of Zoology, University of Otago, PO Box 56, Dunedin, New Zealand. \\ ${ }^{\dagger}$ Present address: K.N. Mouritsen, Department of Marine Ecology, Aarhus University, Finlandsgade 14, DK-8200 Aarhus N, Denmark. \\ *Corresponding author, e-mail: robert.poulin@stonebow.otago.ac.nz
}

\begin{abstract}
In a field experiment, the accumulation of trematode (Echinostomatidae) metacercariae by the New Zealand cockle Austrovenus stutchburyi was compared among treatments with different seabed hydrodynamics and sedimentation rates. There was no significant difference among the treatments in the rate at which cockles accumulated metacercariae, suggesting that infection rates are not influenced by water flow conditions within the normal range experienced in natural habitats. There was, however, substantial spatial variation in infection rates among the experimental plots. This result indicates that metacercarial accumulation varies horizontally as well as vertically within the intertidal zone.
\end{abstract}

\section{INTRODUCTION}

Given their lifespan and swimming capabilities and the spatial scale on which transmission takes place, the freeliving infective stages of parasitic trematodes appear likely to be affected by environmental factors. Trematode cercariae use numerous behavioural adaptations to enhance their transmission from the snail first intermediate host to the second intermediate host (Combes et al., 1994; McCarthy et al., 2002). Still, several biotic and abiotic variables can greatly decrease their transmission success (e.g. Rea \& Irwin, 1994; Cross et al., 2001). Most previous studies on cercarial swimming behaviour and how it is affected by environmental conditions have been performed under controlled laboratory conditions; therefore little is known about cercarial transmission under field conditions. Trematodes are key forces modulating host population dynamics and community structure in many systems, particularly intertidal ecosystems (Sousa, 1991; Mouritsen \& Poulin, 2002), and better information is needed on what affects cercarial transmission in nature.

Here, rates of cercarial infection were examined in the field using a common host-parasite system of the New Zealand soft-sediment intertidal zone. An experiment was conducted in which small-scale hydrodynamic conditions at the sediment-water interface, where cercarial transmission occurs, were varied among three treatments. The study system involved the parasite Curtuteria australis (Trematoda: Echinostomatidae), its snail first intermediate host (the whelk, Cominella glandiformis) and its bivalve second intermediate host (the New Zealand cockle, Austrovenus stutchburyi). Cercariae shed by whelks are sucked into the inhalant siphon of cockles, where they encyst as metacercariae in the foot of the bivalve. Metacercariae can live up to a year in their cockle host, whereas the latter has a lifespan of several years. Cockles normally live buried $2-3 \mathrm{~cm}$ below the sediment surface. However, cockles harbouring large numbers of metacercariae are incapable of burrowing and end up stranded on the sediment surface, where they are more susceptible to predation by oystercatchers, the parasite's definitive host (Thomas \& Poulin, 1998; Mouritsen, 2002). A second echinostome trematode species, closely related to Curtuteria australis, also occurs in the study area; although less abundant, it has the same life cycle and effect on cockles as C. australis (Babirat et al., 2004). The parasiteinduced occurrence of numerous cockles on the sediment surface results in increased physical heterogeneity of the habitat: surface cockles provide a substrate for the attachment of epifaunal organisms, and their presence also affects water flow and sediment deposition. In a longterm field experiment aimed at quantifying the impact of these parasite-induced physical changes to the sediment habitat on the intertidal community, Mouritsen \& Poulin (2004) have shown that the total number of both individuals and species of invertebrates settling on experimental plots were significantly higher in plots where the density of surface cockles was artificially increased. Deposition of fine sediment particles was also greater in plots with higher than normal densities of surface cockles (Mouritsen \& Poulin, 2004), indicating altered seabed hydrodynamics and pockets of slow water flow over those plots.

If the altered flow of water over dense patches of surface cockles influences the host-finding efficiency of cercariae, the changed accumulation rate of metacercariae in cockles can have important consequences for the system. On the one hand, if cercarial transmission is reduced in areas of high densities of surface cockles, the average intensities of infection in cockles in those patches will decrease over time, and the patches would thus be ephemeral because of the negative feedback on cercarial transmission. On the other hand, if cercarial transmission is facilitated in areas of high densities of surface cockles, the average intensities of infection in cockles in those patches will remain high over time; the positive feedback would result in the patches being self-perpetuating. In this study, we explore these possibilities using data on differential accumulation rates of metacercariae among live 
cockles from the plots with altered densities of surface cockles in the experiment by Mouritsen \& Poulin (2004). We also use these data to examine small-scale spatial variation in rates of metacercarial accumulation. This is one of the first studies to examine the effect of physical habitat features on cercarial transmission under field conditions, and it does so in a system where cercarial transmission success has eventual community-wide consequences (Mouritsen \& Poulin, 2004).

\section{MATERIALS AND METHODS}

The experiment was carried out on the mudflat at Gills Corner in the Otago Harbour, South Island, New Zealand, from the austral spring to the autumn (November 2001 to May 2002). A randomized block design was used, with the three treatments (see below) randomized within seven blocks. Each block thus consisted of three experimental plots, separated from each other by $2 \mathrm{~m}$, for a total of 21 experimental plots. The blocks were located along a transect parallel to the waterline and situated toward the low water mark (approximately two hours of air exposure per tidal cycle).

The experimental units were $1 \mathrm{~m} \times 1 \mathrm{~m}$ plots on which the densities of surface cockles were manipulated, with either 0,30 or 100 surface cockles added per plot. Because local intensities of infection are moderate, there are very few naturally-occurring surface cockles at Gills Corner, and thus the numbers added correspond closely to the actual experimental densities of surface cockles in the three treatments. A grid of fine nylon lines was placed over each plot, anchored at the corners by pegs pushed into the sediments; depending on the treatment, there were either 0,30 or 100 cockles attached to this grid. These 'cockles' were actually clean cockle shells glued shut (with a clay pellet inside to provide natural buoyancy) and attached to the nylon lines in random positions within the $1 \mathrm{~m}^{2}$ plot. The use of these cockle mimics allowed us to control their size (mean \pm SE, $31.2 \pm 0.3 \mathrm{~mm}$ ) and movements, and ensured that the densities remained constant during the 6-month long experiment. At the end of the experiment five core samples $\left(0.012 \mathrm{~m}^{2}\right.$ area, $15 \mathrm{~cm}$ deep) were taken in each plot; these were used to sample the invertebrate community living both on and in the sediments (see Mouritsen \& Poulin, 2004), but also served to collect live cockles that remained within the plots over the course of the experiment, and thus experienced different local conditions and possibly different rates of trematode accumulation. All cockles from these core samples were preserved in $4 \%$ formaldehyde for later dissections.

There were between two and 14 cockles per core sample; in samples with five or fewer cockles, all were processed, but in samples with six or more cockles, only the five largest were used. Each cockle was measured (maximum shell length) and then dissected. The foot, where the metacercariae are encysted, was removed and digested in a pepsin solution $(6 \mathrm{~g}$ pepsin and $7 \mathrm{ml} \mathrm{HCl}$ in $1000 \mathrm{ml}$ water) at $40^{\circ} \mathrm{C}$ for a few hours. All metacercariae were then counted under a dissecting microscope $(\times 10)$.

Separate two-way analysis of variance (ANOVAs) were used to compare numbers of cockles per core sample and cockle shell sizes among treatments and blocks. Since cockles sampled from the different treatments could not have differed in intensity of infection at the start of the experiment, because of the random allocation of treatments within blocks, any difference at the end can only be due to different accumulation rates during the experiment. Numbers of metacercariae per cockle were $\log _{10}(x+1)$ transformed to meet the assumptions of normality. An analysis of covariance (ANCOVA), with shell length as a covariate, was then used to evaluate the effect of treatment and blocks (and their interaction) on numbers of metacercariae per cockle.

\section{RESULTS}

In total, we obtained data from 481 cockles, with a mean shell length $( \pm \mathrm{SE})$ of $28.8 \pm 0.2 \mathrm{~mm}$. Numbers of metacercariae in these cockles ranged from 0 to 531, with an average of 152 per cockle.

Numbers of cockles per core sample did not differ among treatments or blocks (ANOVA: treatment, $F_{2,84}=0.357, \quad P=0.7007$; blocks, $F_{6,84}=0.621, \quad P=0.7131$; interaction, $\left.F_{12,84}=0.291, P=0.9894\right)$. However, the size of cockles varied significantly among blocks, and almost among treatments too (ANOVA: treatment, $F_{2,460}=2.823$, $P=0.06$; blocks, $F_{6,460}=2.875, \quad P=0.009$; interaction, $F_{12,460}=1.387, P=0.168$ ). In absolute terms, this variation is not large (about $3.5 \mathrm{~mm}$ between the smallest and largest mean values; Figure 1). Since the numbers of cockles per core sample did not vary among blocks and treatments, the observed variation in cockle sizes is not an artefact of the fact that we only dissected the five largest cockles per sample when a sample included more than five cockles. Mean cockle size values do not show a monotonic change along the blocks, from one end of the transect to the other (Figure 1); instead, they vary erratically, suggesting small-scale horizontal variation in shell sizes that existed prior to the experiment.

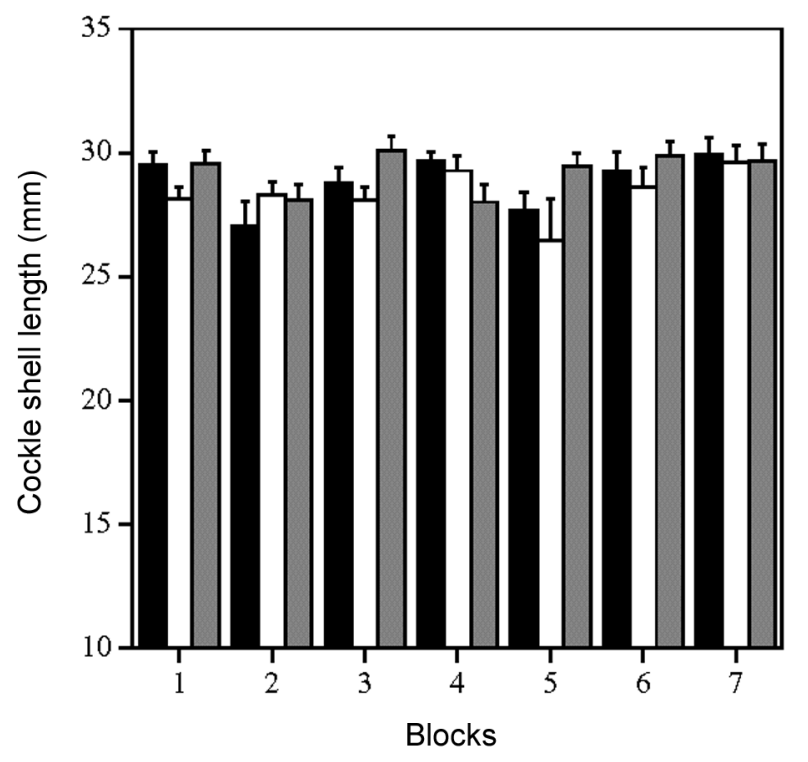

Figure 1. Mean $( \pm \mathrm{SE})$ shell length of cockles Austrovenus stutchburyi sampled from the three experimental treatments and the seven blocks. The treatments correspond to experimental plots in which either 0,30 or 100 surface cockles were added per $\mathrm{m}^{2}$ (black, open and shaded bars, respectively). Numbers of cockles per group range between 20 and 25. 


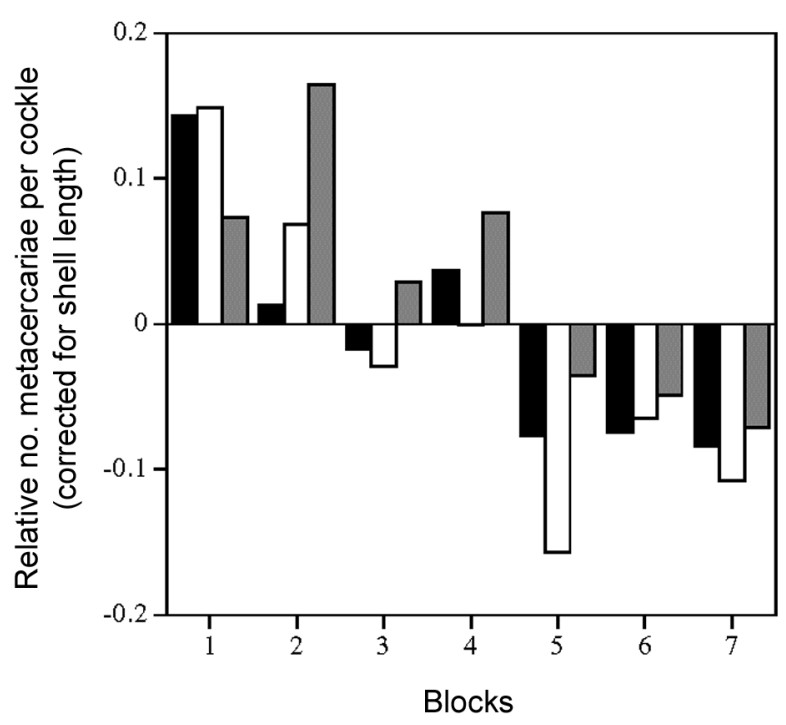

Figure 2. Mean number of metacercariae per cockle, for each of the three experimental treatments and the seven blocks. The values shown are mean residuals from the regression of $\log _{10}(x+1)$-transformed numbers of metacercariae against shell length, and are thus corrected for cockle size. Positive values indicate a greater number of metacercariae than that expected from cockle size, whereas negative values indicate fewer metacercariae than expected. Standard errors are not shown because they are all very similar, ranging from 0.057 to 0.079 . The treatments correspond to experimental plots in which either 0,30 or 100 surface cockles were added per $\mathrm{m}^{2}$ (black, open and shaded bars, respectively). Numbers of cockles per group range between 20 and 25 .

Numbers of metacercariae per cockle correlated positively with cockle shell size, and also varied significantly among blocks independently of shell size (ANCOVA: shell size as covariate, $\quad \mathrm{F}_{1,459}=278.862, \quad r^{2}=0.381$, $P=0.0001 ;$ treatment, $F_{2,459}=0.917, \quad P=0.400 ;$ blocks, $F_{6,459}=4.681, \quad P=0.0001 ; \quad$ interaction, $\quad F_{12,459}=0.368$, $P=0.974)$. The variation among blocks showed a clear pattern along the transect, with cockles in blocks at one end of the transect harbouring more metacercariae than expected from their shell sizes, and those from blocks at the other end of the transect harbouring fewer metacercariae than expected from their shell sizes (Figure 2).

\section{DISCUSSION}

Given the important role of trematode parasites in the structuring and functioning of intertidal communities (Sousa, 1991; Mouritsen \& Poulin, 2002), elucidating the factors which generate small-scale variation in infection levels in natural host populations is crucial. Here, we have shown that under field conditions, small changes in water flow causing a significant increase in the deposition of fine sediments (Mouritsen \& Poulin, 2004) have no detectable effects on the rate at which metacercariae of echinostome trematodes accumulate in cockles. We expected that these changes would affect cercarial transmission, because the latter occurs at the sediment-water interface. Our findings highlight the importance of estimating cercarial transmission rates in the field, under fully natural conditions, when assessing the potential role of environmental factors.

Earlier studies have shown that changes in water flow can affect the transmission of cercariae in living in freshwater habitats (e.g. Webbe, 1966; Wetzel \& Shreve, 2003). More recently, a laboratory study on the echinostome Himasthla elongata, a species closely related to Curtuteria australis, has found little effect of increasing water flow on cercarial transmission success (de Montaudouin et al., 1998). Similarly, laboratory studies have shown that cercariae of $H$. rhigedana can swim faster than the water flow in turbulent eddies characteristic of their natural habitat under normal weather conditions (Fingerut et al., 2003). Perhaps cercariae of $C$. australis, H. elongata and $H$. rhigedana, and those of echinostomes in general, are sufficiently strong swimmers to overcome any changes in water flow on the order of those created in our experiment.

Small-scale spatial variation in rates of metacercarial accumulation exists in the echinostome-cockle system. As one moves from the lower to the upper shore, mean numbers of metacercariae per cockle generally increase, whereas mean cockle shell size decreases (Poulin et al., 2000; Mouritsen et al., 2003). Vertical gradients in infection intensities are known from similar systems (e.g. Lim $\&$ Green, 1991). The differences among our experimental blocks, and the pattern in Figure 2, indicate that there are also horizontal gradients in infection levels among cockles, on a scale of metres. These exist independently from our treatments, and must have existed at the onset of the experiment.

We can exclude two possible explanations for this horizontal gradient in infection intensity. Firstly, the first intermediate hosts of the trematode, the whelks Cominella glandiformis, may for some reason have been present at different densities along our transect, with their density steadily decreasing from block one to block seven. This would mean that all else being equal (i.e. the prevalence of infection in snails being constant among blocks), the total number of cercariae released per day per unit area would decrease from block one to block seven. This could generate the pattern shown in Figure 2. As part of our larger experiment (Mouritsen \& Poulin, 2004), we sampled whelks from all experimental plots using a device that covered $0.25 \mathrm{~m}^{2}$ in each plot. There was no significant difference in whelk density among the blocks (Mouritsen \& Poulin, 2004), and there was also no relationship between mean whelk density per block and mean number of metacercariae per cockle, corrected for shell length $\left(\mathrm{N}=7, r^{2}=0.009, P=0.8393\right)$. These whelk samples were only collected at the end of the experiment and do not represent average densities over the duration of the experiment. Still, there is no evidence that variation in densities of first intermediate hosts can account for horizontal variation in metacercarial accumulation rates in the second intermediate hosts.

Secondly, small differences in water coverage time among the blocks could possibly explain the pattern seen in Figure 2, as well as some of the variation in mean cockle sizes among blocks. Although we set the transect along which the blocks were located parallel to the waterline, the surface of the mudflat is slightly uneven. Thus, blocks six and seven were consistently the first, and blocks one and two the last, to be submerged when the tide came in, 
and vice versa when it went out. The differences in exposure times are mere minutes, however, and unlikely to be the reason for the observed gradient. Other possible explanations include larger-scale hydrodynamic processes, or horizontal gradients in the densities of organisms capable of preying on cercariae.

We thank Amy Armstrong and David Latham for technical assistance. This research was partially funded by grants to R.P. from the Marsden Fund and to K.M. from the Danish Natural Science Research Council.

\section{REFERENCES}

Babirat, C., Mouritsen, K.N. \& Poulin, R., 2004. Equal partnership: two trematode species, not one, manipulate the burrowing behaviour of the New Zealand cockle, Austrovenus stutchburyi. Fournal of Helminthology, 78, 195-199.

Combes, C., Fournier, A., Moné, H. \& Théron, A., 1994. Behaviours in trematode cercariae that enhance parasite transmission: patterns and processes. Parasitology, 109, S3-S13.

Cross, M.A., Irwin, S.W.B. \& Fitzpatrick, S.M., 2001. Effects of heavy metal pollution on swimming and longevity in cercariae of Cryptocotyle lingua (Digenea: Heterophyidae). Parasitology, 123, 499-507.

Fingerut, J.T., Zimmer, G.A. \& Zimmer, R.K., 2003. Larval swimming overpowers turbulent mixing and facilitates transmission of a marine parasite. Ecology, 84, 2502-2515.

Lim, S.S.L. \& Green, R.H., 1991. The relationship between parasite load, crawling behaviour, and growth rate of Macoma balthica (L.) (Mollusca, Pelecypoda) from Hudson Bay, Canada. Canadian Fournal of Zoology, 69, 2202-2208.

McCarthy, H.O., Fitzpatrick, S. \& Irwin, S.W.B., 2002. Life history and life cycles: production and behavior of trematode cercariae in relation to host exploitation and next-host characteristics. Fournal of Parasitology, 88, 910-918.

Montaudouin, X. de, Wegeberg, A.M., Jensen, K.T. \& Sauriau, P.G., 1998. Infection characteristics of Himasthla elongata cercariae in cockles as a function of water current. Diseases of Aquatic Organisms, 34, 63-70.
Mouritsen, K.N., 2002. The parasite-induced surfacing behaviour in the cockle Austrovenus stutchburyi: a test of an alternative hypothesis and identification of potential mechanisms. Parasitology, 124, 521-528.

Mouritsen, K.N., McKechnie, S., Meenken, E., Toynbee, J.L. \& Poulin, R., 2003. Spatial heterogeneity in parasite loads in the New Zealand cockle: the importance of host condition and density. Fournal of the Marine Biological Association of the United Kingdom, 83, 307-310.

Mouritsen, K.N. \& Poulin, R., 2002. Parasitism, community structure and biodiversity in intertidal ecosystems. Parasitology, 124, S101-S117.

Mouritsen, K.N. \& Poulin, R., 2004. Parasite boosts biodiversity and changes animal community structure by trait-mediated indirect effects. Oikos, in press.

Poulin, R., Steeper, M.J. \& Miller, A.A., 2000. Non-random patterns of host use by the different parasite species exploiting a cockle population. Parasitology, 121, 289-295.

Rea, J.G. \& Irwin, S.W.B., 1994. The ecology of host-finding behaviour and parasite transmission: past and future perspectives. Parasitology, 109, S31-S39.

Sousa, W.P., 1991. Can models of soft-sediment community structure be complete without parasites? American Zoologist, 31, 821-830.

Thomas, F. \& Poulin, R., 1998. Manipulation of a mollusc by a trophically transmitted parasite: convergent evolution or phylogenetic inheritance? Parasitology, 116, 431-436.

Webbe, G., 1966. The effect of water velocities on the infection of animals exposed to Schistosoma mansoni cercariae. Annals of Tropical Medicine and Parasitology, 60, 78-84.

Wetzel, E.J. \& Shreve, E.W., 2003. The influence of habitat on the distribution and abundance of metacercariae of Macravestibulum obtusicaudum (Pronocephalidae) in a small Indiana stream. Fournal of Parasitology, 89, 1088-1090.

Submitted 19 May 2004. Accepted 13 September 2004. 